\title{
MANUSIA DAN LINGKUNGAN DALAM CERPEN INDONESIA KONTEMPORER: ANALISIS EKOKRITIK CERPEN PILIHAN KOMPAS
}

\author{
Novita Dewi \\ Pascasarjana Universitas Sanata Dharma Yogyakarta \\ email: novitadewi@usd.ac.id
}

\begin{abstract}
Abstrak
Penelitian bertujuan mendeskripsikan pilihan politis-ideologis yang ditampilkan melalui hubungan manusia dan lingkungan dalam cerpen Indonesia kontemporer. Tujuannya adalah untuk menakar apakah sastra Indonesia masa kini telah memperlihatkan keberpihakan yang serius dalam upaya menghadang kehancuran bumi karena ulah manusia. Sumber data penelitian adalah cerpen di surat kabar Kompas 2010 - 2015, yang bertemakan lingkungan hidup. Melalui metode pembacaan kritis dan teori Ekokritik ditemukan hal-hal sebagai berikut. Pertama, sejumlah cerpen mengambil lingkungan hidup hanya sebagai latar tempat dan waktu. Kedua, cerpen-cerpen dengan tema pencemaran air telah menyuarakan ikrar politis memerangi perusakan lingkungan. Ketiga, sastra hijau, yakni sastra berperspektif Ekokritik, belum menjadi arus utama dalam sastra Indonesia kontemporer.
\end{abstract}

Kata kunci: sastra hijau, Ekokritik, cerpen Indonesia kontemporer

\section{PEOPLE AND ENVIRONMENTS IN CONTEMPORARY INDONESIAN SHORT STORIES: AN ECOCRITICISM ANALYSIS OF SHORT STORIES SELECTED BY KOMPAS}

\begin{abstract}
This study aims to describe political-ideological choices manifested in the relationship between people and environments in contemporary Indonesian short stories. The objective is to assess whether or not the present Indonesian literature has shown serious alignment in an attempt to prevent the destruction of the Earth because of human acts. The data sources were short stories with environmental themes in Kompas newspaper issued in 2010 - 2015. Through critical reading and Ecocriticism theory, the findings are as follows. First, a number of short stories use environments only as spatial and temporal settings. Second, short stories with water pollution themes have expressed a political pledge to prevent environmental destruction. Third, green literature, namely literature with the ecocriticism perspective, has not been the main stream in the contemporary Indonesian literature.
\end{abstract}

Keywords: green literature, Ecocriticism, contemporary Indonesian short stories

\section{PENDAHULUAN}

Krisis ekologi dan dampak pencemaran lingkungan makin mencengkeram perhatian dunia saat ini. Perilaku manusia terhadap alam dan eksploitasi besar-besaran terhadapnya telah mendorong dunia menuju kerusakan ekologis yang berkepanjangan sekaligus mengancam keberlangsungan hidup manusia itu sendiri. Lebih-lebih jika diperhitungkan dimensi sosial-ekonomi dan konsekuensi psikologis dari krisis lingkungan tersebut, tam- 
pak nyata bahwa kaum miskinlah yang paling dirugikan. Indonesia, misalnya merupakan salah satu negara yang didera krisis ekologi akibat pembalakan hutan dan polusi air. Menurut catatan Blacksmith Institute di New York, Sungai Citarum menjadi sungai dengan polusi tertinggi di dunia pada tahun 2013. Sungai terpanjang dan terbesar di Jawa Barat ini, seperti dilaporkan dalam National Geographic Indonesia (April 2014), menjadi tidak bersahabat lagi bahkan cenderung buas di musim hujan bagi puluhan juta warga miskin yang tinggal dan menggantungkan hidup di wilayah sungai itu. Pertambahan jumlah penduduk yang seakan berlomba dengan bertumbuhnya industri di kawasan sekitarnya menjadikan Sungai Citarum pembuangan sampah terbesar di planet bumi. Ini hanya salah satu contoh dari jutaan bencana dan ketidakadilan terhadap masyarakat terpinggirkan yang terjadi karena perlakuan semena-mena manusia terhadap alam.

Mirip dengan problem lingkungan hidup di Malaysia (Mamat et al., 2011; Zainal, 2013) dan Pakistan (Salam, 2011), misalnya, pembangunan besar-besaran, penebangan hutan, dan urbanisasi di Indonesia telah mempengaruhi lingkungan secara umum, yakni polusi udara, pencemaran sungai, pencemaran limbah industri dan pertanian, serta deforestasi. Bahkan menurut laporan Direktorat Riset dan Kajian Strategis IPB, Indonesia menjadi beban dunia dalam krisis global karena penggundulan hutan, penggunaan produk rekayasa pertanian non-organik, pencemaran lingkungan, dan dampak sosial-budaya lainnya (Hunga, 2013).

Paus Fransiskus baru-baru ini menerbitkan Ensiklik ekologis Laudato Si (Terpujilah Engkau) yang ditanggapi secara positif dari kalangan akademisi di berbagai kawasan dunia termasuk para aktivis kemanusiaan dan lingkungan, serta para pengambil kebijakan pada level internasional (PBB) karena pendekatannya ter- hadap persoalan lingkungan yang dinilai komprehensif dan menggerakkan solidaritas. Menurut pemimpin tertinggi gereja Katolik ini, pemecahan masalah ekologis yang sejati selalu berupa pendekatan sosial, yakni mengintegrasikan masalah keadilan dalam diskusi lingkungan hidup guna mendengarkan jeritan bumi maupun jeritan kaum miskin. Bumi adalah anugerah Sang Pencipta dan manusia sebagai makhluk yang berakal budi haruslah memeliharanya, bukan mengeksploitasi sekehendak hati demi kepentingan bersama. Kesadaran dan tanggung jawab ekologis merupakan tanggung-jawab moral sekaligus tanggung-jawab iman.

Jelaslah di sini bahwa masalah ekologis tidak terlepas begitu saja dari masalah manusia yang bertindak atau berbuat, karena hal ini menyangkut pemilihan nilainilai atau "masalah etis" (Sastrapratedja, 2013: 169). Pendapat ini bersetuju dengan pandangan salah satu pakar lingkungan hidup, Emil Salim, yang menyorot ketimpangan pembangunan yang tidak memperhatikan dampak sosial dan lingkungan. Dalam makalah yang ditulisnya untuk Sidang Tahunan Konferensi Wali-gereja Indonesia 2012 tentang Ekopastoral dengan tema "Keterlibatan Gereja dalam Melestarikan Keutuhan Ciptaan" (2013), Salim mengharapkan semua pemimpin masyarakat beragama mengambil prakarsa dalam tugas mulia mengelola sumber daya alam dan melestarikan keutuhan ciptaan secara bertanggung-jawab. Maka dapat dikatakan di sini bahwa masalah lingkungan hidup tidak bisa ditempatkan secara terbatas pada wilayah sains saja, karena hal ini menyangkut tanggung jawab moral, etis, dan kemanusiaan yang lebih besar.

Mengingat bahwa pilihan moral dan pembentukan karakter merupakan bagian yang tak terpisahkan dari fenomena bahasa dan sastra, penelitian tentang sejauh mana masalah lingkungan hidup ini ditanggapi oleh kajian sastra menjadi pen- 
ting. Pada hakekatnya, membaca dan menulis karya sastra adalah mengasah akal budi dan perasaan manusia, dengan cara memahami dan berempati pada berbagai pengalaman hidup manusia. Pe-ngalaman ini secara kreatif dan imajinatif dihadirkan oleh pengarang dalam bentuk puisi, cerpen, novel, drama, dan lain sebagainya.

Sayang sekali kajian sastra tentang lingkungan hidup di Indonesia masih terbatas karena hal ini berkaitan dengan terbatasnya pula karya sastra berperspektif ekologi. Terdapat pelbagai imajinasi alam di dalam karya sastra. Kritik lingkungan hidup merupakan representasi yang paling radikal dibandingkan dengan pujian terhadap keindahan alam seperti dalam puisi atau novel beraliran romantisme ataupun hujatan atas kekejaman alam (terhadap manusia) yang tampak pada karya sastra bermazhab naturalistis-realis/deter ministis (Clark, 2011).

Keindahan alam dan panorama tanah air yang menakjubkan, misalnya, dapat dijumpai pada puisi-puisi lama Muhammad Yamin dan dalam novel-novel sejak periode sastra Balai Pustaka, Pujangga Baru, hingga karya-karya kontemporer. Refleksi yang mendalam tentang dampak pencemaran lingkungan dan bencana alam tidak begitu terbaca karena pada umumnya pengarang lebih sering mengusung persoalan-persoalan sosial-politik (dan ekonomi) di Indonesia dari zaman ke zaman.

Di antara langkanya kritik lingkungan dalam sastra, novel karya Martin Aleida Jamangilak Tak Pernah Menangis (2002) merupakan gugatan terhadap Sungai Asahan yang dianiaya oleh sebuah pabrik rayon multinasional. Perempuan yang menjadi tokoh utama dalam novel ini berupaya melawan pemerintah tapi usahanya digagalkan oleh konspirasi politik dan kapitalisme (Bandel, 2008). Dalam cerita pendek "Kering" karya Wa Ode Wulan Ratna (2006), pembalakan hutan di Pekanbaru, Riau menjadi persoalan yang dihadapi oleh tokoh-tokoh dalam cerita tersebut. Suryaningsih (2013) membaca dominasi patriarki atas alam dan perempuan pada cerpen ini. Penelitian Wiyatmi (2014) atas novel Amba karya Laksmi Pamuncak, misalnya, menunjukkan bahwa eksploitasi yang dilakukan rejim pemerintah (Orde Baru) tidak hanya berdimensi politis tetapi juga ekonomis dan kapitalis, di mana kekayaan alam Pulau Buru seperti tambang minyak, pohon kayu putih dan yang lainnya menjadikan pulau tersebut surga bagi para investor asing. Melalui pembacaan Eko Kritik, terlihat ada wilayah ekonomipolitik yang disembunyikan di balik penggambaran seram Pulau Buru yang sengaja dikonstruksikan oleh penguasa. Pembacaan berwawasan lingkungan semacam ini amat diperlukan untuk memperkaya kajian sastra tanah air.

Kajian sastra lingkungan hidup perlu digalakkan mengingat sumbangannya terhadap urgensi penanganan krisis ekologi dewasa ini. Karena itu, Seminar Nasional yang digelar oleh Jurusan Pendidikan Bahasa dan Sastra Indonesia, FBS, Universitas Negeri Yogyakarta November 2014 yang lalu, misalnya, merupakan pilihan moral-intelektual yang patut diapresiasi. Penelitian ini merupakan pengembangan dari gagasan yang dibentang dalam kegiatan tersebut, yakni perlunya sains dan implikasi sosialnya seperti masalah lingkungan hidup diretas oleh sastra sehingga kajian sastra sungguh memberikan kontribusi kepada masalah-masalah nyata dalam masyarakat. Meskipun imajinasi pelestarian alam telah tercermin dalam beberapa karya sastra tanah air, masihperlu diteliti lebih lanjutsejauh manakah karya-karya tersebut menyapa dan menggugah kesadaran manusia akan dampak pengrusakan lingkungan hidup.

Penelitian ini bertujuan melihat bagaimana masalah lingkungan hidup diimajinasikan dalam karya sastra yang relatif mudah diakses oleh masyarakat luas, yaitu melalui cerpen-cerpen yang terbit di 
harian nasional. Menurut Bandel (2006:53) "sastra koran" merupakan bentuk karya yang mutu sastrawinya masih diperdebatkan namun popularitas dan penerimaannya sangat besar di kalangan pembaca Indonesia. Di dunia Barat pun jenis sastra semacam ini digemari dan, seperti dilaporkan oleh Page (2002) dalam The Bookseller, sastra koran yang dibukukan menjadi salah satu buku laris (http://www. thebookseller.com/news/short-storynewspaper-hits-bookshops). Fenomena yang sama ditunjukkan oleh terbitnya buku kumpulan cerpen Kompas sejak awal 2000-an. Inilah yang mendasari dipilihnyacerpen-cerpen terbitan Kompas dalam penelitian ini, dengan asumsi bahwa wacana naratif semacam ini barangkali cukup mewakili suara hati bangsa Indonesia yang didera oleh persoalan lingkungan hidup.

Adapun masalah-masalah penelitian ini dirumuskan sebagai berikut. Pertama, bagaimanakah persoalan lingkungan hidup ditampilkan dalam cerpen-cerpen yang dimuat di harian Kompas dari 2010 hingga pertengahan 2015. Kedua, dalam pandangan Ekokritik, bagaimanakah cerpen-cerpen tersebut menunjukkan keberpihakan pada masyarakat kecil yang menjadi korban perusakan lingkungan. Ketiga, bagaimanakah cerpen-cerpen tadi dipetakan dalam cerpen Indonesia kontemporer, jika dibandingkan dengan cerpen lain yang tidak mengambil lingkungan hidup sebagai tema.

\section{METODE}

Sastra sebagai produk anak zaman menjadi landasan konseptual penelitian ini. Oleh karena itu, perlu dicermati secara kualitatif dan kritis bagaimana jagad sastra dewasa ini menerjemahkan masalahmasalah nyata yang dihadapi masyarakat seperti pengrusakan lingkungan hidup. Penelitian ini memakai data primer berupa cerpen-cerpen bernuansa lingkungan yang terbit di harian Kompas pada kurun
2010 - 2015. Selanjutnya, data sekunder berupa kajian-kajian terdahulu baik tentang sastra hijau maupun beberapa kajian terkait untuk memperoleh gambaran yang lebih lengkap mengenai pelbagai refleksi atas persoalan lingkungan hidup.

Analisis data diawali dengan membaca secara cepat semua cerpen yang diunggah lewat situs https://lakonhidup. wordpress.com dan http://cerpen.print. kompas.com dari tahun 2010 sampai dengan pertengahan 2015. Kemudian semua cerpen yang diterbitkan oleh Kompas yang bertemakan lingkungan hidup ditandai untuk dibaca lebih lanjut. Data cerpen pilihan Kompas juga diperoleh dari versi cetak dalam berbagai volume buku Kumpulan Cerpen Kompas dan beberapa cerpen yang terbit dalam harian Kompas edisi Minggu hingga Juni 2015. Dari data yang ada, terkumpul sejumlah 25 (dua puluh lima) cerpen untuk dibaca lebih lanjut sebagai sumber data terpilih.

Hasil pembacaan kemudian dikelompokkan dengan pertimbangan: (1) cerpen yang mengambil lingkungan hidup sebagai latar tempat dan waktu, (2) cerpen bertemakan lingkungan hidup dengan simbol-simbol tertentu, yaitu pohon dan air, (3) cerpen yang melibatkan tokoh utama dalam konflik seputar lingkungan hidup. Setelah itu, dengan menggunakan prinsip dasar Ekokritik, cerpen-cerpen tersebut dibaca berulang-ulang untuk mendapatkan pemahaman yang mendalam. Teori Ekokritik didapat terutama dari buah pikir Buell (2001) yang berpendapat bahwa Ekokritisisme harus dijalankan sejalan dengan komitmen dan praksis (bukan hanya teori) para pejuang lingkungan hidup. Selain itu, dipakai pula sebagai acuan jurnal-jurnal mutakhir tentang sastra lingkungan hidup, antara lain Journal of Ecocriticism. Dokumen penting lain untuk membaca keberpihakan pemecahan masalah lingkungan pada masyarakat miskin didapat dari Ensiklik Paus Fransiskus Laodato si' (2015). 
Hasil interpretasi divalidasi dengan kutipan-kutipan dari teks yang diteliti. Pada sejumah cerpen yang pernah ditelaah sebelumnya, temuan yang baru diperbandingkan dengan temuan lain yang dilacak lewat pemberitaan di surat kabar, jurnal ilmiah, serta laporan penelitian yang memiliki kemiripan pada aspekaspek tertentu sebagai pendukung. Hasil pembacaan ini disimpulkan untuk menjawab masalah penelitian (1) dan (2): kehadiran dan keberpihakan sastra bertemakan lingkungan hidup. Selanjutnya, cerpen-cerpen bernuansa ekologis lainnya yang diterbitkan selama 2010 - 2015 oleh Republika, Jawa Pos, Media Indonesia, Suara Merdeka, dan Koran Tempo dibaca sekali lagi sebagai pembanding untuk menjawab masalah penelitian (3): posisi sastra lingkungan hidup dalam khasanah cerpen Indonesia kontemporer.

\section{HASIL DAN PEMBAHASAN}

Pada subbagian ini diuraikan hasil penelitian dan pembahasan tiga hal yang menjadi fokus penelitian, yakni imajinasi krisis lingkungan hidup, gambaran bencana alam dan keberpihakan, dan perspektif ekologis dalam sastra Indonesia. Ketiga hal tersebut disajikan dalam sub-subab berikut.

\section{Imajinasi Krisis Lingkungan Hidup da- lam Sastra Indonesia}

Isu lingkungan hidup digarap oleh para cerpenis dengan menunjuk secara langsung ke lingkungan yang tercederai, khususnya pohon/hutan dan air, ataupun secara abstraksi dengan memakai simbolsimbol yang imajinatif. Dari 25 cerpen yang diteliti, terdapat 16 cerpen yang mengambil pohon sebagai tema (baik pelestarian maupun pemusnahannya), 8 cerpen dengan tema air, dan 1 cerpen yang berbau mitologi, khususnya mitos kuda air. Ditunjukkan pula dalam penelitian ini bahwa pohon lebih kerap difungsikan untuk memberi makna metaforik daripada fisik.
Selain itu, pohon juga kadang dihadirkan hanya untuk memperkuat latar sebuah cerita. Sebagai contoh, cerpen "Pohon Hayat" karya Mashdar Zainal,"Menebang Pohon Silsilah" karya Indra Tranggono (17 Februari 2013) dan "Di Kaki Hariara Dua Puluh Tahun Kemudian" oleh Martin Aleida (Kompas, 23 Mei 2010) menampilkan pohon sebagai latar tempat, sehingga isu ekologis tidak begitu diolah dalam ketiga cerpen ini. Satu daun artinya satu kehidupan kata nenek dalam "Pohon Hayat". Setiap penduduk di kotanya tersemat di tiap daun yang bertengger di cabang, ranting, dan tangkai pohon itu. Maka ketika ada satu daun yang jatuh, pastilah seseorang di kota tersebut mati.

Demikian pula dalam "Menebang Pohon Silsilah", pohon dikisahkan sebagai penanda tempat dan waktu bagi pergumulan setiap tokoh dalam cerpen. Sementara itu, dalam cerpen Martin Aleida, pohon hariara menjadi saksi keteladanan seorang guru sekolah. Kartika Suryani mendidik para siswa untuk berani jujur dan berkeadilan. Rupanya sejak guru bantu ini diberhentikan karena konflik dengan pihak pimpinan sekolah, anak-anak selalu mengubur surat-surat pribadi dan catatan refleksi mereka di kaki pohon. Maka ketika 20 tahun kemudian mereka bersama-sama menggali tanah di kaki hariara yang telah keriput dan harus ditebang untuk pengembangan gedung sekolah, nyatalah bahwa pembelajaran tentang kejujuran dan kebebasan telah ditanamkan dan pohon hariara adalah saksinya. Meskipun ketiga cerpen ini menebarkan nilai-nilai kemanusiaan, dalam pandangan Eko Kritik masih terasa adanya getaran antroposentrisme karena alam (pohon) hadir untuk pemenuhan kebutuhan kultural manusia (Clark, 2011).

Ketika pohon dipakai sebagai simbol, masalah lingkungan hidup justru menjadi lebih mengemuka. Dalam cerpen-cerpen berikut ini, pohon ditampilkan sebagai metaforakehidupan: "Rongga" karya Novi- 
ana Kusumawardhani (29 Agustus 2010), "Ketapang Kencana" karya Bre Redana (21 November 2010), “Pohon Jejawi” oleh Budi Darma (26 Desember 2010), “Ketika Pohon Itu Masih Mekar" tulisan Doni Jaya (13 Februari 2011), "Sebatang Pohon di Loftus Road" karya Sungging Raga (14 April 2013), dan cerpen pemenang anugerah Kompas "Di Tubuh Tarra, Dalam Rahim Pohon" karya Faisal Oddang (4 Mei 2014). Lewat tokoh-tokoh yang peduli, cerpen-cerpen tersebut menggam-barkan bahwa manusia bertanggungjawab atas masalah lingkungan hidup, yakni hilangnya keanekaragaman hayati, rontoknya nilai-nilai arkeologi lokal, kerusakan lahan pertanian, degradasi kualitas lingkungan, dan sebagainya. Pohon Cincau dalam cerpen Doni Jaya yang selalu dijaga kelestariannya oleh Mama akhirnya meranggas dan mati setelah Mama terjatuh dari pohon itu. Imajinasi alam yang mistis dan supranatural kadang diselipkan seperti pada "Pohon Jejawi" (Maimunah, 2014) dan "Di Tubuh Tarra, Dalam Rahim Pohon". Pada "Wiro Seledri" (10 Juli 2011), cerpen GM Sudarta ini tidak berbicara soal pohon besar, tetapi tanaman perdu bernama seledri yang disuburkan oleh kotoran manusia - suatu kiat dari penulis yang dipelajarinya sewaktu mendekam di Pulau Buru.

Selain pohon tunggal, hutan juga sering diangkat dalam beberapa cerpen bernuansa ekologis. Hutan yang tercederai, misalnya hadir dalam cerpen "Ulat Bulu \& Syekh Daun Jati" oleh Agus Noor (28 Juli 2013). Ada nuansa mistis dan legenda di sini yang memberi pelajaran moral bagi pelanggar keseimbangan alam.

Kampung seperti diselubungi cairan hitam karena seluruhnya tertutup ulat bulu. Seluruh batang pohon tertutup ulat bulu hitam hingga ke ujung cabang-cabangnya. Atap-atap rumah dipenuhi ulat bulu. Segalanya menjadi tampak menghitam. Juga hutan jati yang mengelilingi kampung itu. Tiap batang pohon jati tertutup ulat bulu. Hutan jati itu menjadi hutan hitam yang begitu mengerikan. Tak ada pemandangan yang begitu hitam melebihi hitamnya hutan jati yang telah menjadi begitu mengerikan oleh jutaan ulat bulu. Seakan-akan di tengah-tengah kehitaman hutan jati itu hidup arwah-arwah penasaran yang haus mengisap darah siapa pun yang berani memasukinya (http://cerpen. print.kompas.com/2013/07/28/ulat-bulusyekh-daun-jati/)

Hutan dalam cerpen "Tulisan Kelinci Merah" karya Afrizal Malna (11 November 2012) memberi manusia moderen pelajaran tentang kearifan lokal. Cerpen ini berlatar kehidupan Urang Kanekes, Baduy penganut agama Buhun yang telah ada sebelum politheisme dan monotheisme. Setiap tahun penduduk yang menyatu dengan alam ini mengadakan Upacara Seren di hutan yang dilindungi oleh pikukuh dan ketentuan adat yang tak boleh dilanggar. Tanah merupakan harta penting yang tak boleh diusik - "Tanah tidak boleh digali, dipacul atau dibajak. Kontur tanah harus tetap terjaga dari erosi. Tanah hanya boleh ditusuk dengan bambu yang ujungnya telah diruncingi untuk kemudian ditanami." Listrik, sabun, dan piranti peradaban modern lain tak boleh digunakan warga. Mereka menyatu dengan alam:

Pendeta Bumi menyatakan tiga syarat untuk bisa membebaskan diri dari bumi: melanggar adat istiadat, menjadi gila atau bunuh diri. Ketiga orang makhluk itu seperti terbakar men-dengar persyaratan itu. Mereka sudah tidak tahan berada di bumi. Tidak tahan berada bersama planet yang tidak masuk akal ini, di mana kehidupan dijalani hanya untuk menunggu datangnya kematian. Dan selama penungguan itu, orang menciptakan berbagai versi kehidupan: berbuat jahat kepada orang lain atau berbuat baik. Membunuh orang lain atau menyelamatkan orang lain. Menguasai atau membebaskan. Merampok orang lain atau menolong orang lain. Korupsi atau hidup dari kerja keras yang dilaku- 
kan sendiri. Bertemu atau berpisah. Mengakui kepercayaannya sendiri, tetapi menyerang kepercayaan yang lain. (https:// lakonhidup.wordpress.com/2012/11/11/ tulisan-kelinci-merah/\#more-3533)

Dengan menjaga harmoni hutan, terjaga pula harmoni kehidupan antar manusia: "Mereka mengikuti jalan air, bukan jalan api. Antiperang, melukai atau membunuh. Kalau kamu mau hidup, yang lain juga boleh hidup".

"Romansa Merah Jambu" karya K. Usman (19 September 2010) bercerita tentang raibnya sebuah hutan dengan danau yang begitu indah di tepinya yang pernah menjadi sumber inspirasi sekaligus saksi cinta. Dulu seorang pelukis sering datang ke danau yang berair biru jernih itu bersama anak lelakinya. Gadis kecil sebaya yang dulu menjadi teman bermainnya kini telah beranjak dewasa, dan dengan setia selalu menunggu sang kekasih sambil menyulam di tepi danau seusai memanen padi di ladang bersama Bapak dan Emak. Keindahan alam itu dilukiskan demikian:

Di keheningan tepi danau tercium oleh [Gadis] harum bunga mawar hutan. Dia dengar nyanyian burung dan hiruk pikuk kawanan kera. Dia melihat gelepar ekor ikan di permukaan danau. Air beriak bagaikan tersibak. Di atas tebing, daun pepohonan sangat rimbun-bercermin di air danau yang bening. (https://lakonhidup.wordpress.com/2010/09/21/ romansa-merah-jambu/\#more-784)

Lalu pada paragraf berikutnya yang sekaligus merupakan paragraf pungkasan, pengarang menampilkan perubahan cepat yang terjadi atas alam dan manusianya. Kutipan di bawah ini memperjelas hal tersebut.

Sekian tahun silam, menjelang petang, seorang pelukis tua berjanggut lebat, dan putranya datang dari kota ke ladang di tepi hutan itu. Pemuda tampan itu menyetir mobil jip tua dan membantu sang ayah membawa peralatan melukis. Bapak dan Emak Si Gadis mengizinkan Si Pelukis dan putranya memasang tenda di tepi ladang. Perupa itu berniat melukis fauna dan flora di hutan sekitar itu. Dia juga mau melukis peladang, pengail ikan di sekitar danau, mawar hutan, dan pemandangan alam. Di ujung tahun, Gindo menyetir jip tua peninggalan ayahnya menuju danau. Dia tercengang di depan pagar besi tinggi berkawat duri. Dirasakannya pagar yang menghadang itu sangat angkuh. Ladang dan hutan tak tampak lagi. Tanaman kelapa sawit muda setinggi lutut-terbentang di depannya seluas mata memandang. Danau makin sunyi. Pemancing tua entah berada di mana? Tak ada lagi pepohonan tinggi yang berdaun rimbun di sekitar danau itu. Gindo tidak diizinkan masuk lokasi perkebunan sawit oleh petugas keamanan berseragam hijau-loreng. Para petugas keamanan itu tidak dapat menjawab pertanyaan Gindo, "Di mana Emak, Bapak, dan Gadis, setelah hutan, dan ladang mereka digusur?" (https://lakonhidup. word press.com/2010/09/21/romansamerah-jambu/\#more-784)

Seperti K. Usman, dalam cerpennya "Rongga", Noviana Kusumawardhani mengkritisi penebangan hutan atas izin kepala desa yang keponakan jenderal itu. Pohon-pohon perlu ditebangi karena akan dibangun taman moderen untuk melengkapi supermarket dan mal yang sudah ada agar masyarakat menjadi lebih bahagia. Adalah Kemplu jagoan desa yang mati-matian mempertahankan pohon tua berongga tempat ia menyepi dan mencurahkan kesedihannya melihat desa yang telah banyak berubah itu. Ternyata masyarakat menjadi berani bersuara dan ikut mendukung upayanya sebelum buldozer membabat habis semua pohon di sana.

Hutan itu tetap berfungsi sebagai ruang publik. Sekarang justru bernama Taman Air Mata. Siapa pun bisa dan boleh menangis sepuas-puasnya. Bahkan pengunjung taman yang sedang gembira dan 
ingin merasakan bagaimana indahnya kesedihan di taman itu bisa membeli obat perangsang kesedihan yang ditawarkan petugas penyobek tiket tanda masuk. Setiap pengunjung sebelum pulang akan menyempatkan berfoto di pohon Kemplu, demikian mereka menyebut satu-satunya pohon yang tidak di tebang itu. Pohon yang merindang. https:// lakonhidup.wordpress.com/2010/08/31/ rongga/\#more-706)

Selanjutnya, dalam penelitian ini didapati pula bahwa alam kadang-kadang ditampilkan secara ganas, terutama pada cerpen seputar hujan dan banjir. Misalnya, hujan telah lama tak turun karena ditahan oleh seorang pawang desa dalam "Mbah Simbad Si Pawang Hujan". Cerpen Aba Mardjani (4 Agustus 2013) ini menyoal pergulatan antara kepentingan pribadi dan kepentingan umum. Kontraktor yang tak ingin rugi meminta Embah Simbad menahan hujan agar proyek jalan tolnya selesai tepat waktu, sementara penduduk telah berbulan-bulan mengalami kekeringan sumur dan tanaman mulai meranggas. Namun akhirnya Simbad menyerah. Hujan turun juga karena ada pawang-pawang hebat lainnya yang disewa untuk menahan hujan bagi berbagai keperluan dari pesta perkawinan sampai pemakaman seorang jenderal. Kejayaan Embah Simbad pun tumbang disaksikan oleh Maksun seorang pengagumnya:

Simbad tersenyum. "Bukan menyerah, Maksun. Tapi biarlah hujan turun dulu supaya warga di sini juga senang. Kau kan tahu, setelah terakhir hujan kulepas? Itu sekitar dua minggu lalu. Hampir dua puluh hari malah. Jadi, biarlah tanah mendapatkan haknya mendapatkan siraman hujan."

Setelah berkata begitu, Mbah Simbad melangkah pergi menerabas derasnya hujan, meninggalkan Maksun dan beberapa orang lain yang masih merasa tak puas dengan penjelasannya. Beberapa saat kemudian, tubuhnya hilang ditelan derasnya hujan dan angin.
Menjelang magrib, hujan berhenti menyisakan gerimis. Menerabas sisa-sisa genangan air di jalan, Maksun mencari Mbah Simbad yang dikaguminya. Dari kejauhan ia melihat tubuh pawang pengusir hujan itu di gubuknya. Seperti tengah bersujud. Tanpa gerak. Maksun mengendus bebauan daging terbakar. (https:// lakonhidup.wordpress.com/2013/08/04/ mbah-simbad-si-pawang-hujan/\#more4347)

Sebelumnya, Aba Mardjani telah mengolah tema hujan dan banjir dalam "Banjir di Cibaresah" (28 Oktober 2012) yang akan dibahas lebih terinci pada bagian selanjutnya dari tulisan ini.

Penelitian ini menunjukkan bahwa pada beberapa cerpen bertema bencana alam, seakan diabaikan kenyataan bahwa masalah ekologi adalah akibat tragis dari aktivitas manusia yang tak terkendali. Dalam pandangan Ekokritisisme, manusia tidak melihat makna lain dari lingkungan alam selain yang bermanfaat untuk segera dipakai dan dikonsumsi; sehingga ketika alam memberontak, manusialah yang merasa dirugikan.

Dalam "Muslihat Hujan Panas" karya Benny Arnas (11 Agustus 2013), misalnya, alam bukan sahabat bagi tokoh Maisarah yang telah merenggut nyawa kedua anaknya. Kekesalannya bertambah karena Samin bekas suaminya yang seorang veteran itu menemuinya lagi setelah sepuluh tahun tak kembali dan berkeluh-kesah tentang kondisi keuangannya.

Sungguh, ketakutan, kebencian, dan rasa trauma Maisarah pada hujan panas tak lagi tertakar. Dua anaknya yang baru menginjak remaja meninggal dunia karenanya. Mursal ditemukan mengapung di bantaran Sungai Kasie di kaki Bukit Sulap. Sekujur tubuhnya membiru, perutnya buncit oleh air. Ia memang sangat gemar mandi di dekat lubuk di siang hari. Sudah sering orang-orang mengingatkan tapi sesering itu pula ia mengabaikannya. Bahkan, seperti di siang naas itu, ketika hujan panas pun, ia bersikeras menceburkan diri 
di lubuk seorang diri. Sepandai apa pun ia berenang, ketika air pasang tak kepalang, hanya ada dua kemungkinan baginya: pusaran lubuk akan mengisapnya atau arus pasang akan menyeretnya hingga tubuhnya mengapung.

Dua tahun berikutnya, Badri, adik Mursal, menyusul. Di usia yang sama dengan meninggalnya si kakak, Badri tewas jatuh dari pohon kelapa dengan tubuh terbakar. Ia disambar petir ketika sedang memetik kelapa muda di perkebunan Haji Maulana di siang bedengkang. Memang tak ada yang menyangka kalau awan berwarna santan dapat menurunkan hujan dan diterabas petir. (https://lakonhidup.wordpress.com/2013/08/11/muslihat-hujanpanas/\#more-3960)

Bahwa alam bisa menjadi kawan atau pun lawan juga nampak dalam paragraf pembuka cerpen Anton Kurnia "Rumah Air" (27 April 2014) berikut ini:

JIKA hujan singgah, Mamah akan gelisah. Hujan memang anugerah. Pohon-pohon yang kekeringan, daun-daun yang kehausan, dan rumput-rumput yang ranggas akan senang menerima guyuran air segar basah. Tapi hujan juga bisa jadi musibah. Air yang melimpah-ruah tapi tak lancar mengalir bakal menjadi banjir. Rumah kami yang mungil pun dipaksa menjadi rumah air. (https://lakonhidup.wordpress. com/2014/04/27/rumah-air/\#more-4813)

Sering tidak disadari bahwa kerusakan alam juga disebabkan oleh intervensi manusia. Ekokritisisme menggugat hal ini karena alam yang merupakan bagian yang tak terpisahkan dari manusia itu keberadaannya bukan untuk dieksploitasi saja, melainkan juga harus dilestarikan. Maka, kesimpulan sementara dapat ditarik di sini bahwa pada banyak cerpen yang dikaji, masalah lingkungan hidup belum menjadi agenda yang politis, tetapi sekedar retorika ekologis (Buell, 2001). Lebih banyak cerpen yang menyuguhkan ratapan atas masalah lingkungan hidup tanpa memberikan solusi. Namun demikian, imajinasi musibah yang lebih apokaliptis tampak lebih terpapar dalam cerpen-cerpen bertema polusi air.

\section{Gambaran Bencana Alam dan Keberpi- hakan}

Ramalan Rachel Carson lewat Silent Spring kerap menjadi pijakan teori Ekokritik yang akopaliptik,misalnya dari Buell (2001) dan Philips (2008). Penelitian ini memakai Ekokritisisme apokaliptik dan dokumen Ekologi yang gayut dengannya dari Paus Fransiskus Laudato si' (2015) sebagai piranti analisis cerpen-cerpen yang dikaji. Pada Ensiklik No. 25 disebutkan bahwa dalam beberapa dekade mendatang dampak terburuk perubahan ilkim dan pemanasan global akan dirasakan oleh negara-negara berkembang di mana kaum papa lah yang paling dirugikan karena penghidupan mereka sangat tergantung pada cadangan alam dan jasa ekosistem seperti pertanian, perikanan, dan kehutanan. Masyarakat miskin tidak memiliki sumber keuangan atau sumber daya lain yang memungkinkan mereka untuk beradaptasi dengan perubahan iklim atau menghadapi bencana alam. Bahkan akses mereka memperoleh perlindungan dan pelayanan sosial juga terbatas. Imajinasi ketimpangan sosial dan ketidakadilan pembangunan mengemuka dalam cerpen-cerpen berikut.

"Banjir di Cibaresah" karya Aba Marjani menunjukkan keberpihakan pada kaum miskin ketika pengusaha besar dan penguasa pemerintah mengeksploitasi alam. Dikisahkan sudah berhari-hari desa Cibaresah direndam air. Banjir seakan menghukum warga desa Cibaresah karena para petinggi pemerintah yang korup. Mereka bekerjasama dengan pengembang bisnis properti yang merugikan masyarakat. Koruptor-koruptor itu dihadirkan dengan simbol-simbol binatang yang dikenal sebagai musuh manusia seperti tikus, ular, buaya, dan sebagainya. 
“Mungkin karena makin banyak vila berdiri, makin sedikit daerah resapan air, dan sungai-sungai makin menyempit," Maksum menggumam. "Orangorang makin tak peduli pada ruang untuk air."

[...]

Dari kejauhan, Maksum dan Kasdul melihat macan belang itu berjongkok di depan pintu rumah kepala desa. Di jendela-jendela, serigala bertengger diam. Buaya-buaya besar berseliweran di sekeliling rumah besar itu bersama banyak sekali ular berkepala dua. Dinding-dindingnya penuh kecoa dan cacing. Sesekali terdengar lolong anjing dan dengus babi. Tikus-tikus nampak asyik bermain-main. Kupu-kupu beterbangan. Sebagian keluar masuk ke dalam rumah. Sesekali, berkelebat warna hitam setansetan seolah mengancam siapa pun yang berani mendekati rumah itu. (https:// lakonhidup.wordpress.com/2012/11/07/ banjir-di-cibaresah/\#more-3501)

Ketimpangan sosial juga ditampilkan dalam "Protes" karya Putu Wijaya (23 November 2013) dengan cerita tentang rumah hantu yang sengaja ditebar oleh pemilik bisnis perumahan, dan "Ikan Kaleng" oleh Eko Triono (15 Mei 2011). Cerpen-cerpen ini menggugat retorika pembangunan masyarakat pedalaman yang tidak sepenuhnya menyejahterakan mereka. Dalam "Ikan Kaleng", misalnya, orang-orang suku Lat dikirim ke kota untuk memperoleh pendidikan dan belajar menangkap ikan secara moderen sekaligus mengawetkannya. Namun ketika suatu hari kepala suku Lat sendiri pergi ke Jayapura untuk memasarkan ikan, terkejutlah ia ketika tahu bahwa harga sebuah ikan kaleng ternyata sama dengan harga satu kilogram ikan mentah. Sejakitu, bertekadlah ia mendatangi sekolah yang bisa mengajarkan murid-muridnya membuat ikan kaleng (https://lakonhidup.wordpress.com/2011/05/15/ikan-kaleng/\#more2054).
Dengan memakai gaya nostalgia dalam bercerita, Kurnia JR dalam cerpennya "Cikapundung" (9 Juni 2013) meratapi keruhnya Sungai Cikapundung yang dulu "cantik memikat, meliuk-liuk genit bagai gadis remaja" tapi sekarang bak naga setengah lumpuh yang"merayap seraya meratap, sedang kota terus tumbuh, dipadati manusia". Tak terlihat lagi di sana rumpun bambu, anak-anak, dan kaum perempuan yang mandi atau mencuci baju.

Sehabis pukulan bertubi-tubi, kutengok dunia masa kecilku. Sungguh, aku tak terkejut mendapati sungaiku merana. Bukan hanya dia yang habis-habisan diperkosa manusia. Ciliwung, Cisadane, Citarum, serta seribu sungai lain hanya bisa melata lungkrah. Air jernih dibalas dengan limbah.

[...]

Di sini akan kuhabiskan sisa usia sebab di sini ada sahabat setia yang kupercaya untuk menitipkan cerita-cerita. Seperti juga aku, dia sudah tua, tidak segemilang dulu. Tidak terdengar lagi gemercik arus yang riang spontan atau air yang jernih. Limbah manusia telah menodai kemurniannya yang naif. Cikapundung sungai yang dirundung murung. (https:// lakonhidup.wordpress.com/2013/06/09/ cikapundung/\#more-4127)

Sama seperti tangisan atas keruhnya Sungai Cikapundung, melalui cerpen "Bidadari Serayu" (6 April 2014), Sungging Raga berkisah tentang upaya penyadaran masyarakat tentang polusi air dan dampaknya bagi masyarakat kelas bawah yang hidup di bantaran Sungai Serayu. Meski penuh kontroversi, cerita dihembuskan tentang bidadari pencabut nyawa karena terhitung telah 14 orang didapati mati di sungai itu sejak 1886 ! Bidadari khayangan enggan mandi di situ karena Serayu tak hijau lagi. Sejak cerita bergulir, tidak ada lagi warga yang berani membuang kotoran, sampah, dan buang air besar di kali itu. Maka, meski 
tak sehijau seperti semula dan tak lagi menjadi tempat persinggahan bidadari, "sungai itu tak hendak mengutuk siapa pun, ia membiarkan segala cerita hanyut bersama alirannya yang tetap tenang, begitu tenang, sampai ke Pantai Selatan...." (https://lakonhidup.word press. com/2014/04/06/bidadari-serayu/\#more4718). Meskipun masih samar, cerpen ini mencoba memperlihatkan keprihatinan terhadap isu pencemaran, dibandingkan dengan cerpen Sungging Raga sebelumnya yang hanya memakai sungai sebagai latar tempat semisal "Serayu, Sepanjang Angin Akan Berembus..." (Kompas, 22 Juli 2012).

Selain kritik atas sungai-sungai yang ternodai, protes terhadap ketidakadilan pembangunan juga menjadi inti "Mengenang Kota Hilang" (Kompas, 13 Mei 2012). Diilhami oleh sebait pusi karya Hasan Aspahani (2006): "Maka lumpur pun datang membasuh wajah kota itu", karya R. Giryadi ini mengambil tema bencana lumpur panas di Sidoarjo. Lewat monolognya, tokoh Aku menyampaikan peringatan agar siapapun datang ke kota itu harus mengganti hatinya dengan batu dan mengantongi" sekarung nyawa" karena jalan yang dilewati adalah "jalan maut", yakni rampok kecil dan pengemis dadakan di sepanjang jalan. Kemiskinan akibat bencana alam telah membuat kota itu rawan kejahatan.

Bila kau lolos di jalan maut, kau tak perlu bergembira. Karena setelah itu kau akan menemukan jalan yang bercabangcabang, mirip labirin. Kau harus pandai memilih jalan yang tepat. Bila salah pilih, jangan harap kau bisa kembali menjadi manusia. Kau pasti akan menjadi lintah, atau semacam belut yang hidup di rawa-rawa, yang kini dikuasai oleh monster-monster berwarna-warni. (https:// lakonhidup.wordpress.com/2012/05/21/ mengenang-kota-hilang/\#more-3076)
Selanjutnya, judul "Serpihan di Teras Rumah" pada cerpen Zaidinoor (3 Februari 2012) menunjuk pada semburan debu hitam yang dibawa oleh roda-roda truk yang melintas di depan rumah Ni Siti. Janda Kai Rustam penyadap karet ini tak pernah lagi mendapati getah cair sejak dua tahun terakhir ini ketika perusahaan besar dengan mesin yang meraung-raung memasuki desa perkebunan karetnya. Untuk memberi jalan bagi truk-truk besar, pohon rambutan yang dua puluh tahun yang lalu ditanam Kai Rustam di halaman rumah beratap rumbia itu pun harus ditebang. Di situ diletakkan tong besar yang kata Pembakal (kepala desa) disumbangkan untuk menampung air bersih yang mulai langka. Tong itu terlalu besar dan halaman Ni Siti yang tak terlalu luas itu kini tidak lagi diramaikan oleh anak-anak yang bermain di bawah pohon rambutan. Alhasil, Ni Siti kehilangan sesuatu yang bisa membuatnya merasa dekat dengan sang suami. Ni Siti juga kehilangan pendapatan karena tidak banyak getah yang bisa disadap dari pohon karet di kebunnya. Kritik terhadap ketidakadilan terhadap rakyat kecil demi korporasi besar dinyatakan dengan jelas di akhir cerita sebagai berikut:

Mungkin air dari berbagai tempat mengumpul di lubang-lubang bekas galian itu. Sehingga air di sebelah barat tak lagi mengalir ke kebun karet Ni Siti. Sedang air dari kebun karetnya mengalir menuju lubang. Karet-karet Ni Siti pun kekurangan air. Dan sampai kapan hal ini berlangsung?... Wanita renta itu tak pernah tahu. Ni Siti hanya ingin pulang dan menyapu terasnya.

(https:/lakonhidup.wordpress.com/2013/ 02/03/serpihan-di-teras-rumah/\#more3843)

"Penjaga Kubur Nyai Laras" karya S. Prasetyo Utomo (7 April 2011) juga merupakan sebuah cerpen bernuansa mistis yang bertemakan ketimpangan 
pembangunan. Mandor Karso menentukan pepohonan yang boleh ditebang dan kayu-kayunya diangkut truk pembeli. Batu-batu dipecah, bertumpuk-tumpuk, dan Mandor Karso pula yang menjualnya. Dikisahkan dalam cerpen ini, tempat peristirahatan terakhir Nyai Laras menjadi saksi ketidakadilan itu di mana "binatangbinatang liar penghuni bukit yang masih tersisa, seperti luwak, berlari menghindar, mencari tanah berbukit dan belukar yang tak terenggut tanganmanusia" (https:// lakon hidup.wordpress.com/2013/04/07/ penjaga-kubur-nyai-laras/\#more-3963).

Selain sungai, hutan, dan pohon yang diberi makna harafiah dan simbolis, ada pula cerpen yang memanfaatkan mitos kuda emas. Sama halnya dengan pohon bertuah dalam "Sebatang Pohon di Loftus Road" karya Sungging Raga (14 April 2013), "Kuda Emas" karya Tawakal M Iqbal (22 Juni 2014) berbicara tentang keserakahan manusia. Cerpen ini dipenuhi dengan binatang yang bisa bicara, hewan yang menyamar sebagai manusia. Ini mengingatkan kita bahwa "kita bukanlah tuan dari alam - tetapi kita adalah bagian dari itu":

Sungguh tragis ketika tahu, membutuhkan waktu berjuta-juta tahun untuk menelurkan emas sebanyak itu. Dan di tempat kuda emas bertelur telah dibangun perusahaan tambang besar. Kau tahu, sejak kejadian aku melihat kuda itu terbang dari Tanjoleat menuju Pongkor, kuda itu tak pernah terlihat lagi. Kakek bilang, kuda itu telah terbang dari Papua ke Maluku, lalu ke Kalimantan, Sumatera sebelum akhirnya ke Tanjoleat, kampung kami. Aku khawatir kuda itu kini telah terbang menuju negara lain untuk mencari sarang baru tempatnya bertelur. Sebab di tempat kami, perburuan emas selalu panas. Lagipula, pohon-pohon di Tanjoleat sekarang telah habis. Banyak kedapatan hewan-hewan liar masuk kampung kami. Sekawanan monyet jarang lagi terlihat memanjat-manjat batuan cadas di Tanjoleat. Kini seringkali sepi. (https:// lakonhidup.wordpress.com/2014/06/22/

kuda-emas/\#more-4986)

Dapat disimpulkan di sini bahwamasalah lingkungan hidup ditampilkan di sejumlah cerpen disertai kritik terhadap ketidakadilan bagi orang miskin. Terutama dalam sejumlah "cerpen air", sungai menjadi tercemar karena pembuangan limbah beracun atau imbas gaya hidup perkotaan yang menyebabkan lingkungan hidup terkontaminasi secara fisik, kimiawi, dan sosial. Imajinasi ketimpangan global dan bencana akhir zaman telah diguratkan dalam cerpen-cerpen semacam ini.

\section{Perspektif Ekokritik dalam Sastra In- donesia}

Jika dalam waktu 5 tahun hanya terdapat 25 cerpen yang berwawasan lingkungan, penghitungan sederhana menyimpulkan bahwa harian Kompas tidak memberikan prioritas utama bagi cerpencerpen berperspektif Ekologi. Hanya terdapat rata-rata 5 cerpen pertahun atau sepersepuluh jumlah cerpen yang terbit setiap minggunya dalam setahun. Bagaimanapun juga, pencapaian terbanyak terjadi di tahun 2013 dengan 7 cerpen lingkungan hidup. Setahun sebelumnya terbit Dari Salawat Dedaunan sampai Kunangkunang di Langit Jakarta: 20 Tahun Cerpen Kompas Pilihan, yang meskipun ilustrasi sampul bukunya didominasi oleh warna hijau, hanya memuat 2 dari 23 cerpen pilihan Kompas 2011 yang beraroma ekologis, karena selebihnya dipenuhi cerita yang surealistik dan supranatural.

Selanjutnya, sampul depan Cerpen Kompas Pilihan 2014 juga nampak hijau dari segi fisik. Bahkan cerpen pemenang yang dipilih menjadi judul dan tampil sebagai cerpen pertama, yakni Di Tubuh Rara, dalam Rahim Pohon terdengar hijau. Cerpen Faisal Oddang ini berlatar belakang budaya Toraja. Seorang bayi dikubur dalam pohon Tarra dan menjadi obyek 
pariwisata; bahkan sang ayah sendiri menjual tulang-belulang bayi itu kepada turis karena desakan masalah ekonomi. Meskipun kritik sosial dilontarkan dengan apik oleh pengarang, cerpen ini tetap antroposentris sifatnya dan "tidak hijau". Alam dirawat hanya untuk memenuhi hasrat kutural dan ekonomi manusia. Bagaimanapun juga, di tangan Faisal Oddanglah lahir cerpen "Orang-orang dari Selatan Harus Mati Malam Itu" yang menjadi satu-satunya cerpen hingga Juni 2015 yang memakai pencemaran lingkungan sebagai latar tempat dan waktu. Cerpen ini berkisah tentang orang-orang yang dibantai dalam peristiwa 1965 dan mayat-mayat mereka diceburkan ke sungai sehingga menodai praktik agama asli yang dipercayai penduduk setempat.

Jumlah cerpen bernuansa lingkungan hidup yang diterbitkan di berbagai media lain pada kurun waktu 2010 - 2015 juga kurang menggembirakan. Penelitian ini membaca sekilas tanpa melakukan analisis mendalam atas cerpen-cerpen yang diterbitkan oleh media berikut beserta jumlahnya: Republika (13), Jawa Pos (5), Media Indonesia (4), Suara Merdeka (4), dan Koran Tempo (2). Terdapat 28 cerpen tentang lingkungan hidup yang terbit di kelima surat kabar pada 2010 - 2015. Jika dihitung keseluruhan, maka terdapat 53 cerpen dalam 5 tahun atau kurang dari 11 cerpen dalam setahun. Dari penghitungan ini terlihat bahwa Sastra Hijau belumlah hijau di salah satu negeri dengan krisis ekologi terbesar di dunia.

Sebagai pelengkap bahasan, disajikan nukilan cerpen karya FX Rudy Gunawan "Langit Kalimaya" yang terbit di Media Indonesia pada 14 Desember 2014 sebagai refleksi bersama.

BANDARA dipenuhi oleh ratusan penumpang. Penerbangan mereka tertahan karena asap tebal dari hutan-hutan bakau yang dibakar, hingga memperpendek jarak pandang menjadi sekitar 4-5 meter. Hanya pilot teler yang berani lepas landas di tengah kabut asap seperti itu. Dalam campur aduk kekesalan, kegelisahan, dan kekecewaan ratusan penumpang itu, Husni justru teringat sebuah siang di Ternate. Ia sudah terlalu sering mengalami suasana seperti itu. Pekerjaan sebagai konsultan penanganan limbah industri membuat Husni harus terbang setidaknya seminggu sekali ke berbagai wilayah.

Langit Ternate pada siang itu tak pernah bisa dilupakan Husni. Langit paling aneh yang pernah dilihatnya. Langit yang seperti batu Kalimaya itu menyimpan warna kuning, hijau, dan merah dalam nuansa biru yang membalut semua warna menjadi satu ikatan. Jalin-menjalin sebagai unsur-unsur bebas tapi sekaligus menjadi komposisi yang utuh. Seperti ikatan berbagai unsur kimia yang membentuk senyawa-senyawa dengan berbagai partikel. Husni tak pernah melihat langit seperti itu sebelumnya, meski ia telah menjelajah ke hampir semua pelosok Nusantara. Ia kerap terpesona oleh langit di berbagai daerah yang memiliki keunikan berbedabeda, semacam karakter masing-masing yang mungkin dibentuk oleh mineral, kekayaan tambang, dan hutan-hutan (https://lakonhidup.wordpress. com/2014/12/14/langit-kalimaya/\#more5123)

\section{SIMPULAN}

Krisis ekologis menjadi sumber inspirasi bagi sebagian kecil cerpenis Indonesia. Pada umumnya, cerpen-cerpen yang diteliti mengambil lingkungan hidup hanya sebagai latar tempat dan waktu. Namun demikian, beberapa pengarang telah mencoba melancarkan kritik terhadap pengrusakan lingkungan, terutama penebangan hutan dan polusi air. Polusi air sungai merupakan tema yang paling sering diangkat dalam cerpen bernuansa lingkungan hidup. Cerpen-cerpen yang dikaji mencoba untuk secara kritis menggarisbawahi keseragaman kepentingan masyarakat kota yang mencoba membuat klaim untuk menguasai lingkungan atas nama pembangunan dan pemberantasan kemiskinan. Terdapat hubungan kekua- 
saan antara segelintir kelompok elit versus rakyat kecil, budaya urban versus budaya tradisional. Di sini sungai memiliki arti simbolis yang memisahkan para penguasa dan masyarakat yang terpinggirkan yang hidup di pinggiran sungai.

Jika dibandingkan dengan banyaknya cerpen yang terbit selama kurun waktu yang diteliti, cerpen-cerpen bernuansa lingkungan hidup belumlah memuaskan dalam segi jumlah. Banyaknya isu lingkungan hidup yang hanya dipakai sebagai latar tempat dan peristiwa menjadikan cerpen-cerpen ini retorika ekologi yang menggebu, bukan pertobatan ekologi seperti digagas dalam Laodato si' dan Teori Ekokritik.

Akhirnya, seperti tersirat dalam cerpen-cerpen yang dikaji, bahaya pemanasan global telah menghadang di depan mata. Upaya manusia untuk meningkatkan kehidupan di alam semesta telah menjadi paradoks yang justru mengancam keberadaannya. Di sini meskipun cerpen sebagai bentuk seni kreatif dan kritis mungkin tampak jauh dari laporanpenelitian sains maupun kebijakan publik, secara tidak langsung cerpen-cerpen ini telah menggugah kesadaran budaya yang cinta lingkungan. Ini berarti bahwa sastra bisa berperan sebagai barometer budaya dan agen perubahan.

Oleh karena itu, sebagai usulan dan saran, keberlangsungan atau ketersediaan karya berwawasan lingkungan hidup perlu ditingkatkan baik dalam jumlah maupun kualitas kepedulian apokaliptis yang diusungnya. Perlu dicermati secara kualitatif dan kritis bagaimana jagad sastra Indonesia menerjemahkan masalahmasalah nyata yang dihadapi masyarakat, misalnya perihal pelestarian alam dan/ atau pencemaran lingkungan hidup.

Selain itu perlu dikaji pula keterlibatan penulis dan komunitas sastra lingkungan hidup (sastra sebagai praksis). Misalnya, melalui wawancara intensif dan pengamatan yang berkesinambungan tentang kiprah masing-masing. Barangkali dari sini kelak akan makin berkembang teori pembacaan karya satra khususnya tentang lingkungan hidup. Sebagai tambahan, peninjauan kurikulum pembelajaran sastra dan bahasa perlu pula dilakukan secara teratur dan berkelanjutan; termasuk di dalamya pengembangan desain pembelajaran sastra yang diperkaya dengan Sastra Hijau.

\section{UCAPAN TERIMA KASIH}

Artikel ini merupakan bagian dari penelitian berjudul "Sastra Lingkungan Hidup sebagai Gerakan Sosial: Kajian Karya, Penulis, dan Komunitasnya" yang didanai oleh DP2M Dikti melalui Hibah Penelitian Desentralisasi dengan Skim Penelitian Fundamental 2015. Penulis mengucapkan terima kasih kepada Ketua LPPM Universitas Sanata Dharma dan staf, para reviewer, serta semua pihak atas saran, masukan, dan dukungan yang amat berharga. Semua kekeliruan dan cacat dalam tulisan ini merupakan tanggung jawab penulis sepenuhnya.

\section{DAFTAR PUSTAKA}

Aleida, Martin 2004. Jamangilak Tak Pernah Menangis. Jakarta: Gramedia.

Bandel, Katrin. 2006. "Sastra Koran di Indonesia" dalam Sastra, Perempuan, Seks. Yogyakarat: Jalasutra, hlm. 45 -55 .

Bandel, Katrin. 2008. "Perempuan Pesisir dalam Novel Gadis Pantai dan Jamangilak Tak Pernah Menangis", boemipoetra, November-Desember, hlm. $3-4$.

Buell, Lawrence. 2001. Writing for an Endangered World: Literature, Culture, and Environment in the U.S. and Beyond. Cambridge: Harvard University Press, 2001.

Buell, Lawrence. 2009. The Future of Environmental Criticism: Environmental Crisis and Literary Imagination. London: John Wiley \& Sons. 
Clark, Timothy. 2011. The Cambridge Introduction to Literature and the Environment. Cambridge: Cambridge University Press.

Hunga, Arianti Ina Restiani. 2013. “Ekofeminisme, Krisiss Ekologis, dan Pembangunan Berkelanjutan". Dalam Ekofeminisme dalam Tafsir Agama, Pendidikan, Ekonomi, dan Budaya (ed.) Dewi Candraningrum, Yogyakarta: Jalasutra, hlm. $x$ - xvi.

Maimunah. "Perlawaanan Alam terhadap Kolonialisme dalam Novel Pohon Jejawi [sic] karya Budi Darma" LITERA: Jurnal Penelitian Bahasa, Sastra, dan Pengajarannya, Volume 13, Nomor 2, Oktober 2014, hlm. 326 - 337.

Mamat, Maharam, Johari Talib, and Zulkifli Mohamad. 2011."Environmental Issues in the Literary Works in Malaysia: Preliminary Study of Sarawak Novel Writers"World Review of Business Research, Volume 1, Nomor 4, September, hlm. 115-134.

Page, Benedicte. "Short story 'newspaper' hits bookshops" The Bookseller. Published January 16, 2012.

Paus Fransiskus. 2015. Laudato si'. Vatican City: Libreria Editrice Vaticana.

Phillips, Dana. 2003. The Truth of Ecology: Nature, Culture, and Literature in America. Oxford: Oxford University Press.

Salam, Shazrah. 2011. Unveiling the Sacred: Reading the Gendered Female Body in Contemporary Pakistan Fiction. Unpublished MA Thesis, Massey University, Manawatu, New Zealand.

Salim, Emil. 2013. “Refleksi: Keterlibatan Gereja dalam Melestarikan Keutuhan Ciptaan" Praedicamus, Volume 12, Nomor 41, Januari - Maret, hlm. 7 - 14.

Suryaningsih, Ervin. 2013. “Kendali Patriarki atas Perempuan dan Alam dalam Cerpen Kering (2006) karya Wa Ode Wulan Ratna: Sebuah Kajian Ekofeminisme". Dalam Ekofeminisme dalam Tafsir Agama, Pendidikan, Ekonomi, dan
Budaya (ed.) Dewi Candraningrum, Yogyakarta: Jalasutra, hlm. $31-42$.

Sastrapratedja, M., SJ. 2013.Pendidikan sebagai Humanisasi, Jakarta: Pusat Kajian Filsafat dan Pancasila.

Wiyatmi. "Berziarah ke Pulau Buru melalui Novel Amba Karya Laksmi Pamuncak" Prosiding Seminar Bahasa dan Sastra dalam Perspektif Ekologi dan Multikulturalisme. Yogyakarta: Jurusan Bahasa dan Sastra Indonesia, FBS, UNY, hlm. 301 - 310.

Zainal, Zainor Izat. 2014. “Malaysia's Development Success Story: Critical Responses in Contemporary Malaysian Novels in English" Asian Culture and History, Volume 6, Nomor 1,hlm. 31 42.

Cerpen Koran Minggu. https://lakonhidup. wordpress.com(Diunduh 15 April 2015)

Kumpulan Cerpen Kompas. http://cerpen. print.kompas.com(Diunduh 30 Mei 2015)

National Geographic Indonesia, April 2014.

Lampiran Daftar Cerpen sebagai Data Penelitian Kumpulan Cerpen Kompas. Sumber Data: http://cerpen.print.kompas. com (Diunduh 30 Mei 2015)

1. "Di Kaki Hariara Dua Puluh Tahun Kemudian" karya Martin Aleida (23 Mei 2010)

2. "Rongga" karya Noviana Kusumawardhani (29 Agustus 2010)

3. "Romansa Merah Jambu" karya K. Usman (19 September 2010)

4. "Ketapang Kencana" karya Bre Redana (21 November 2010)

5. "Pohon Jejawi" karya Budi Darma (26 Desember 2010)

6. "Ketika Pohon Itu Masih Mekar" karya Doni Jaya (13 Februari 2011)

7. "Penjaga Kubur Nyai Laras karya S Prasetyo Utomo (7 April 2011)

8. "Ikan Kaleng" karya Eko Triono (15 Mei 2011) 
9. “Wiro Seledri” karya GM Sudarta (10 Juli 2011)

10. "Pohon Hayat" karya Mashdar Zainal (29 Januari 2012)

11. "Serpihan di Teras Rumah" karya Zaidinoor (3 Februari 2012)

12. "Banjir di Cibaresah" karya Aba Mardjani (28 Oktober 2012)

13. "Tulisan Kelinci Merah" karya Afrizal Malna (11 November 2012)

14. "Menebang Pohon Silsilah" karya Indra Tranggono (17 Februari 2013)

15. "Sebatang Pohon di Loftus Road" karya Sungging Raga (14 April 2013)

16. "Cikapundung" karya Kurnia JR (9 Juni 2013)

17. "Ulat Bulu \& Syekh Daun Jati" karya Agus Noor (28 Juli 2013)
18. "Mbah Simbad Si Pawang Hujan" karya Aba Mardjani (4 Agustus 2013)

19. "Muslihat Hujan Panas" karya Benny Arnas (11 Agustus 2013)

20. "Protes" karya Putu Wijaya (23 November 2013)

21. "Bidadari Serayu" karya Sungging Raga (6 April 2014)

22. "Rumah Air" karya Anton Kurnia (27 April 2014)

23. "Di Tubuh Tarra, Dalam Rahim Pohon" karya Faisal Oddang (Kompas, 4 Mei 2014)

24. "Kuda Emas" karya Tawakal M Iqbal (22 Juni 2014)

25. “Orang-orang dari Selatan itu Harus Mati" karya Faisal Oddang (28 Juni 2015) 